\title{
Theory-practice interaction in engineering teaching: Pedagogical experience in the "Management and Treatment of Effluents" course from chemical engineering program
}

\author{
Adriano Gomes Paixão da Silva ${ }^{1}$, Sidmara Bedin ${ }^{2}$, Karine Zanella ${ }^{3}$
}

${ }^{1}$ Department of Chemical Engineering, University of Campinas, Brazil

${ }^{2}$ Department of Chemical Engineering, Federal University of Technology - Paraná, Brazil

${ }^{3}$ Department of Chemical Engineering - Federal University of Latin American Integration, Brazil

\begin{abstract}
Over the years, higher education has been the subject of intense debate and discussion, as the traditional teaching approach, based on theoretical knowledge, concepts and information is no longer sufficient. In chemical engineering courses, this practice is no different, but with the dynamics of the current world and the increasingly competitive job market, it is essential to train professionals with creative, multidisciplinary skills, able to develop reflective thinking. Thus, the crucial challenge in terms of teaching quality in engineering is based on identifying ways to encompass the social and technological changes in the current world in the manner of teaching. An excellent alternative is to increase students' contact with the practice since it allows the execution of theoretical concepts. Therefore, the main objective of this work is to present the importance and positivity of pedagogical experience that occurred with the theory-practice integration implemented in the "Management and Treatment of Effluents" class from Chemical Engineering program at the UNILA, Brazil. A practical activity was developed where students, under the professor's supervision, developed a project of a water treatment plant, after conducting expository classes and technical visits in industries that have wastewater treatment. Once the project was concluded, a survey was sent to the students to gather opinions regarding the activities carried out. From authors and students, this sort of activity represents an interesting tool in the teaching/learning process, since it stimulated the development of some multidisciplinary skills besides the students' motivation in the program.
\end{abstract}

Keywords - chemical engineering, higher education, pedagogical experience, teaching/learning, theorypractice integration.

\section{INTRODUCTION}

Engineering as a profession must improve the world for the good of all, where the professional training of engineers requires the acquisition of a body of specialized knowledge, problem-solving skills and common sense at the service of society. Every professional engineer, therefore, is called not only to achieve a certain degree of intellectual and technical mastery, but also to acquire practical wisdom that brings together knowledge and skills in the way that best serves a specific purpose for the good of humanity. (Sheppard et al., 2006).

The objective of training engineering students is to prepare professionals with a deep knowledge of technical fundamentals and broadly prepared with the necessary skills to work in engineering. (Crawley et al, 2007), where practical activities must be part of the context in the education of future engineers, with the real learning experience of students in the classroom significantly different from learning in the workplace (Cheah \& Yang, 2013).

Technical visits to companies, or any environment in which the future engineer works, are important tools that provide opportunities for students to observe the application of the theory learned in the classroom (Masturah Markom et al., 2011), making students more 
interested and engaged when knowledge and concepts are closer to reality (Barnett \& Coate, 2005).

Student learning outcomes after visits may include the ability to: better visualize processes and products manufactured in industries, improve interpersonal skills, increase awareness of the roles and ethics of engineers and the impacts of industrial processes on health, safety , environment and society (Masturah Markom et al., 2011).

Therefore, the main objective of this work is to present the importance and positivity of the pedagogical experience that occurred with the theory-practice integration implemented in the "Management and Treatment of Effluents" class from Chemical Engineering program at the Federal University of Latin American Integration (UNILA) located in the city of Foz do Iguaçu, Paraná, Brazil.

\section{APPLIED METHODOLOGY}

The Management and Treatment of Effluent course from the Chemical Engineering program at UNILA aim to provide an understanding of the water quality parameters that influence the choice of treatment; To understand how water quality management works; and provide critical analysis of the technologies available for the treatment of effluents, regarding the decision making of the economically viable (Unila, 2020).

With the purpose of making this discipline more dynamic, during the second semester of 2019, a practical activity was developed in which students, under the supervision of the professor, developed a project of a water treatment plant, after conducting theoretical classes and technical visits in local industries that have wastewater and water treatment.

Before the technical visits, the students reviewed the topic seen in the classroom and defined some points to be observed and questioned to the technicians, as they would be visualizing in practice the subject learned theoretically.

The first technical visit was conducted at the poultry industry of Cooperativa Lar, located in the city of Matelândia (PR, Brazil). The poultry unit slaughters an average of 270 thousand birds/day, and there is an environmental concern regarding the industrial waste and water treatment, in which the purification is carried out through several lagoons, which generate biogas and in the later phase, they return to Xaxim river (Lar, 2020). In this visit, the students had the opportunity to see the complete treatment of industrial waste, though, the focus of the visit was to learn how the company performs the poultry slaughter water treatment, i.e. the wastewater.
The second technical visit was carried out at the Companhia de Saneamento do Paraná (Sanepar), in the city of Foz do Iguaçu (PR, Brazil). This company is responsible for providing basic sanitation services to 345 of the 399 cities in the state of Paraná. The company maintains one of the vastest structures in Brazil in basic sanitation, with 168 Water Treatment Plants and more than 55 thousand kilometers of distribution network. The water is treated with chlorine, to guarantee the quality, and with fluorine, to prevent dental caries. Besides, the company follows water quality control and surveillance procedures, determined by the Ministry of Health. (Sanepar, 2020). In this technical visit, the students checked how the water treatment we consume in our homes is carried out step by step and took the opportunity to review any doubts they had up to then.

For the sake of knowledge, a brief explanation of a water treatment plant, represented by Fig. 1, follows.

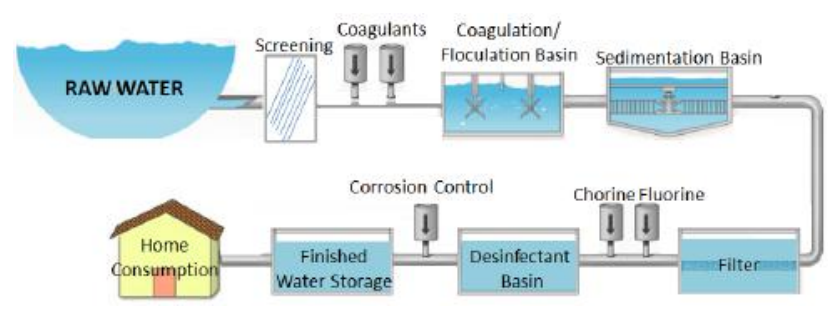

Fig. 1: Water Treatment Plant (Adapted from Denver Water, 2020)

The basic principles into the water treatment process are usually the same, with slightly variations at different locations, depending on the technology of the plant and the water it needs to process (Bittencourt \& De Paula, 2014). A brief explanation of the steps is presented below:

1. Screening: Water passes through the grating to the removal of macroscopic elements, such as leaves, stone and wooden pieces.

2. Coagulation: The $\mathrm{pH}$ is adjusted and water is rapidly mixed with aluminum sulfate, a coagulant that helps the impurities stick together to form bigger particles called floc.

3. Flocculation: In this step, occurs the agitation of the water to favor the union of the particles and the floc has time to grow bigger.

4. Decantation: The heavy floc particles are deposited on the bottom, separating from the water.

5. Filtration: The water passes through gravel, sand and activated charcoal filter to remove floc and any remaining microscopic particles and microorganisms. 
6. Disinfection: Water is disinfected before it enters the distribution system. In this stage occurs the addition of chlorine and fluorine to remove disease-causing microorganisms. Right after this step, the addition of alkaline substances occurs to reduce corrosion in the distribution system and the plumbing.

7. Distribution: The treated water is distributed to the population.

To carry out the practical project, the students were divided into 6 groups, with a maximum of 6 students in each group. Each group had to think about how they would make their water treatment plant. They had a direct channel to ask me questions. They also had a discipline monitor to help them. We didn't interfere in the structure; we just checked if the project's thinking and progress was correct or not.

Considering the discipline project', students had to comply with steps 1 to 5 , and sequences 2,3 , and 4 could be coupled in a single step. The filter should have at least sand, gravel or stone, charcoal, and cloth or cotton, as shown in Fig. 2.

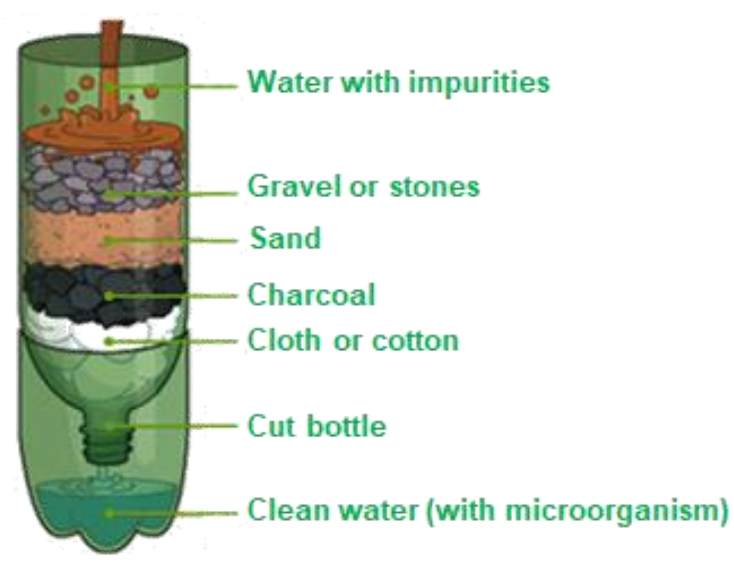

Fig. 2: Water Filter Illustration (Adapted from Sustentável, 2020)

The material carried out to the water treatment plant project was selected by the students, but mostly recycled one was applied. It was also requested that, if possible, they innovated in some stage of the project, arousing even more interest in student participation and, at the same time, interacting with other disciplines.

After theoretical classes and technical visits, the students were able to carry out the water treatment plant project. For the presentation of the project, the students provided the necessary resources in advance, and prepared a pitch presentation, integrating the discipline of Innovation and Entrepreneurship.
Once the project was concluded, a survey (Fig. 3) was sent to the students to gather opinions regarding the activities carried out. Besides, all the students signed a term of authorization and consent for use of image, voice, performance, artwork or likeness (Fig. 4).

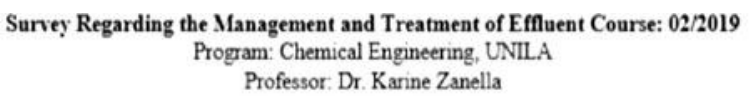

One of the crucial concems about introducing an innovation in the classroom is with the result achieved. In this case, I try to gather from students their opinion about the theory-practice integration of the Water Wastewater Treatment Plant Project elaborated in the course of Management and Treatment of Effluents, of the Chemical Engineering program at the Federal University of Latin American Integration - UNILA, taught in the second academic semester of 2019

I will publish the results of this research in a congress and or article in a scientific joumal. Otherwise, they will contribute to possible improvements in the discipline in question and other ones.

There are two major groups on the survey: Positive and negative points of the project, that is, what you evaluate as positive and negative aspects related to the project. Please be sincere in your answers. The publications will be maintaining the confidentiality and, no personal issues will be applied.

At the end of the survey, I request you to leave a brief statement about what you thought of the project as a whole.

THANK YOU!

PS: You can use as many lines as necessary for your answer. If you do not have an answer to the topic, leave it blank.

Positive and Negative Aspects of the Project

$\checkmark$ Related to the Project preparation stage: $\quad \checkmark$ As for the interaction with other area

$\checkmark$ Related to teamwork: $\checkmark$ As for the pedagogical practice:

$\checkmark$ As for the technical visit: $\checkmark$ Related to skill development:

$\checkmark$ As for the presentation of the Project

Project Statement

Fig. 3: Applied Survey - Translated from the original survey in Portuguese 
TERM OF AUTHORIZATION AND CONSENT FOR USE OF IMAGE, VOICE, PERFORMANCE, ARTWORK OR LIKENESS (Brazilian Copyright Law N. 9.610/98)
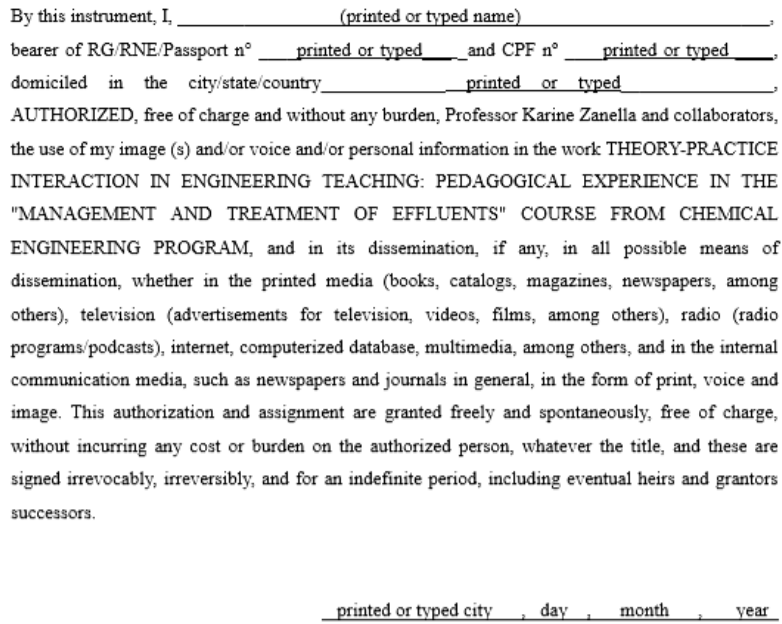

\section{SIGNATURE \\ Fig. 4: Term of authorization and consent - Translated from the original term in Portuguese}

The assessment was carried out exclusively by the professor in charge, making an assessment of all stages of the treatment station and assigning points to each one. The project itself was worth $1 / 3$ of the final grade.

\section{RESULTS AND DISCUSSION}

In this topic, the photographs of the technical visits, of the projects and the students' statements are shown. The most important thing of this project is that the students studied and work by themselves to do the layouts, and were pleased to have done so.

The photographs taken in the technical visits are shown in Fig. 5. The technical visits, as the professor's opinion, were a great teaching tool, because, in addition to providing support in conducting classes, it allows students to contact the practical application of the content learned in the classroom. In addition, students were able to reunite the academic universe with the professional universe, providing participants with a broader education.

In the visits, it was possible to observe the environment of the companies in full operation, to verify their dynamics, organization, and all the theory factors implicit in it. During the technical visit, the objectives were fully achieved, as there was a positive integration between the participants, mainly through the exchange of experiences among students, professors, and professionals in the field.
The students not only found in the companies visited the knowledge acquired in the academic activity, but added personal and professional values, in addition to being even more motivated for the future exercise of the profession in related areas. Given this, it is clear that the technical visits went very well within all programmed expectations and that the class benefited from this type of initiative.
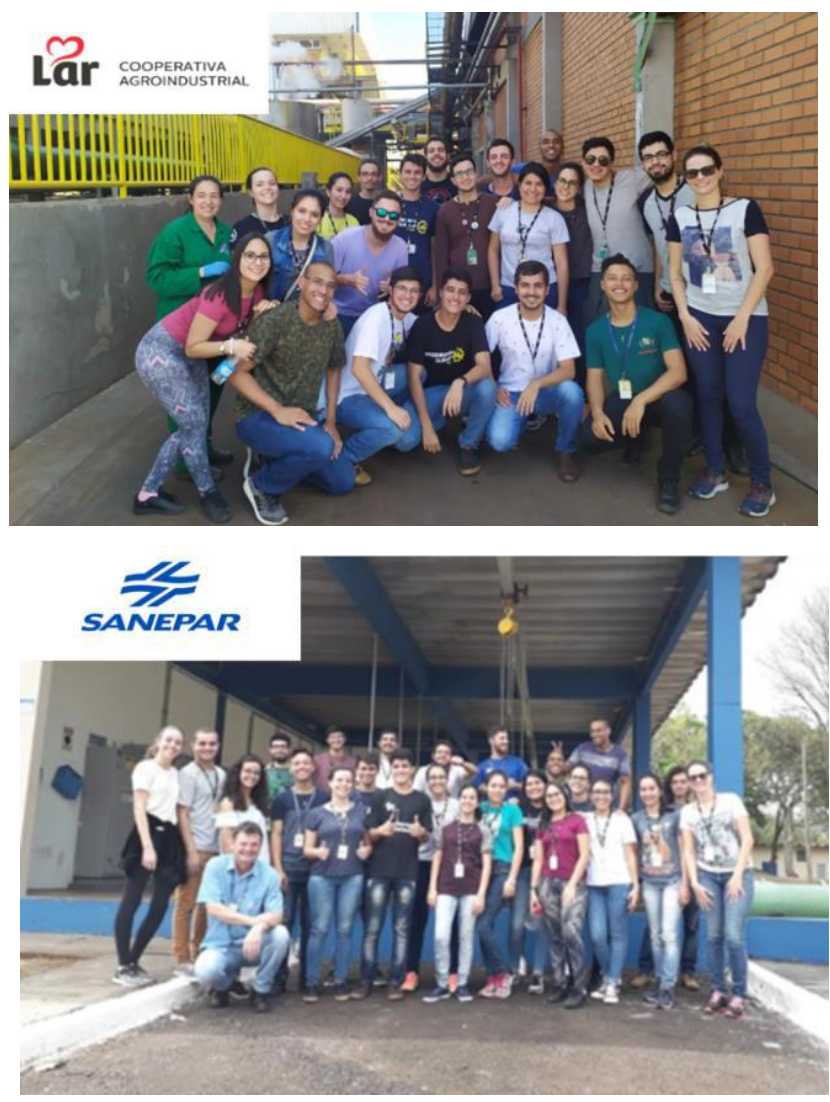

Fig. 5: Technical Visits at Cooperativa Lar and Sanepar.

The photographs of Water Treatment Projects of the six groups are shown in Fig.6.

It is possible to observe in Figure 5, that the groups have diverse structures for water treatment projects, but they all achieved the objective of cleaning contaminated water with soil. The 5th group, placed in its project a barrier for oils and fats (inside the red circle), which is widely used in wastewater treatment. Furthermore, all groups made the filter like the one shown in Figure 2.

The last group (number 6), applied natural Aloe Vera leaf gel as a coagulant, an alternative that has been applied in place of synthetic coagulants, possible causes of toxicity (Borri, Freire, \& Boina, 2014; Rodrigues, Aquino, \& Cordeiro, 2020). The other groups applied aluminum sulfate as a coagulant, and as it was in high concentration, the treated water from this ones, was not tried, as a safety manner. 


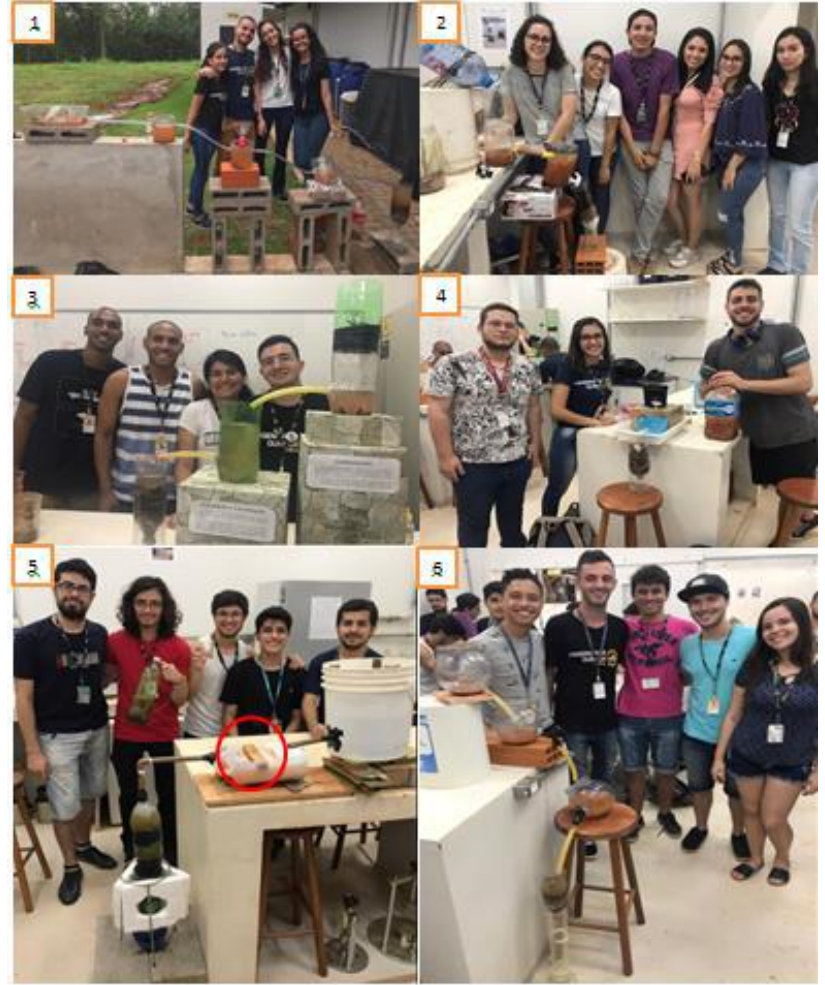

Fig. 6: Students groups with their Water Treatment Plant Project.

This type of research of the group, for a natural alternative as a coagulant, presents itself as the students' engagement in the project, being another proof of how important practical teaching is.

As mentioned before, once the project was conclude, students were asked to answer a survey about their opinions on the project. Some of the students' statements are presented in Table 1, with some highlighted phrases. It is important to share that some statements are not complete.

Table 1: Students' Statements

Students' Statements
“... It was an engaging discipline giving guidance on the
part of my career that I want to concentrate on.” K. Y. G.
A.
"... It was the first time that students had been able to make
a scale model of an engineering process. We ran into
issues that the engineer will have to deal with, such as the
possibility of discussing a project from the beginning with
a group. - A. V.
"... The Water Treatment Plant Project helped to
understand what had been learned in the classroom, besides

it was an alternative way of learning and working then that we are used to.” S. B. C. B.

"In general, the project was intriguing and very enriching. We could think and learn to deal with the error and adversities generated throughout processes. Have the opportunity to assemble from planning to the presentation of a water treatment plant made it possible for me to develop in other ways and to achieve the interdisciplinary that is of us required..."- I. S. Z.

\begin{abstract}
"It was a diverse and advantageous way to learn. When you put into practice the theoretical contents seen in the classroom, it was considerably easier to understand and set what was studied. The technical visits assisted me in understanding each step of the effluent treatment [...] including helping to link the stages that we implemented in the project and to discuss possible ideas to optimize the process" T. M.
\end{abstract}

"In my opinion, having a practical and didactic approach to the content is a great way to understand, remember, and optimize some characteristics of the process. The practice and theoretical contents, together with the technical visit, were necessary to establish the concepts related to a water/wastewater treatment plant...” D.B

"...The implementation of the Water/Wastewater Treatment Plant Project was a very enriching experience, both in the discipline of Effluent Management and Treatment, as well as within the Chemical Engineering Program; because it is not always possible to work practically with concepts developed in the classroom..." M.G.V.

"... A great way to learn anything is through practice and having spaces where you can make mistakes when performing an action, which is not possible with the current educational system. Therefore, initiatives such as taking in the discipline of Effluent Management and Treatment are always welcomed by the students." F. M. C. L.

As main result, from the point of view of the authors and the students themselves, this sort of activity developed represents an interesting tool in the teaching/learning process, since it stimulated the development of some multidisciplinary skills besides the students' motivation in the program.

The students' statements serve as a reference to improvements in the next practical activities carried out, both in the discipline of management and treatment of 
effluents and in other disciplines. Therefore activities can be planned and, the results obtained in the next semesters even more satisfactory.

\section{FINAL CONSIDERATIONS}

During the semester in which the project took place, the theoretical concepts were approached in the classroom, and two technical visits made. In this way, the students could assimilate the theory with the reality of the industries. After that, a project was proposed to the students to put into practice what they have learned.

What we observed in the development of the discipline Management and Treatment of Effluents is that the realization of the Water Treatment Plant project represents a tool of considerable importance for learning. It stimulated motivation, developed skills, and facilitated the relationship between theoretical concepts and the practical application of engineering. Also, the project contributed to increasing the degree of achievement in the discipline since the interest rates changes and, the student starts to dedicate more.

It is worth mentioning that not only did the students 'statements confirm the great results, but some observations in the classroom (such as the students' engagement) were crucial for this teaching dynamics (theory-practice) to be continued and applied in other disciplines.

\section{ACKNOWLEDGEMENTS}

The authors would like to thank the companies where the technical visits were made, and also the students' dedication to the project. Without them, none of this would be possible.

\section{REFERENCES}

[1] Barnett, R., \& Coate, K. (2005). Framing Curriculum. Engaging the Curriculum in Higher Education. Maidenhead: SRHE and Open University Press. Chapter 2.

[2] Bittencourt, C., \& De Paula, M. A. S. (2014). Tratamento de água e efluentes: Fundamentos de saneamento ambiental $e$ gestão de recursos hídricos. São Paulo, SP: Editora Érica.

[3] Borri, R. B., Freire, R., \& Boina, W. L. O. (2014). Remoção da turbidez da água usando aloe vera como coagulante natural. X Fórum Ambiental da Alta Paulista, 10 (12), 01-11.

[4] Crawley, E. F., Malmqvist, J., Ostlund, S. \& Brodeur, D.R. (2007). Rethinking Engineering Education, New York: Springer.

[5] Cheah, S.M., \& Yang, K. (2013). Teaching Engineering Practice in Chemical Engineering via Experiential Learning, Proceedings of the 7th International Symposium on Advances in Technology Education, Japan.
[6] Felder, R. M., Woods, D. R., Stice, J. E., \& Rugarcia, A (2000). The future of engineering education II. Teaching methods that work. Chemical Engineering Education, 34(1), 26-39.

[7] Lar. (2020, August 02). Unidade Industrial de Aves e Carnes - UIA e UIC.

http://www.lar.ind.br/v4/institucional/index.php\#l_industrias ?id=11

[8] Markom, M., Khalil, M. S., Misnon, R., Othman, N. A., Abdullah, S. R. S., \& Mohamad, A. B. (2011). Industrial Talk and Visit for Students. Procedia - Social and Behavioral Sciences, 18, 674-682.

[9] Mobarak, H. M., Wu, H., \& Hossain, M. (2016). Effective Teaching Method for Engineering Education from Student's Perspective. Sydney. International Conference on Engineering Education and Research.

[10] Pott, R. W. M, Wolff, K. E., \& Goosen, N. J. (2017). Using an informal competitive practical to stimulate links between the theoretical and practical in fluid mechanics: A case study in non-assessment driven learning approaches. Education for Chemical Engineers, 21, 1-10. https://doi.org/10.1016/j.ece.2017.08.001

[11] Rodrigues, A. M., Aquino, D. S., \& Cordeiro, L. L. (2020). Avaliação de Aloe arborescens como coagulante para remoção de cor e turbidez em tratamento convencional de água. Ingeniería del agua, 24 (2), 81-88.

[12] Sanepar. (2020, July 19). Água. http://site.sanepar.com.br/asanepar/servicos/agua

[13] Sheppard, S., Colby, A., Macatangay, K., \& Sullivan, W. (2006). What is Engineering Practice? International Journal of Engineering Education, 22(3), 429-438.

[14] Sustentável. (2020, August, 01). Filtro de água caseiro: Como fazer. https://sustentavel.com.br/filtro-de-aguacaseiro/

[15] Unila. (2020, July 21). Projeto Pedagógico do Curso de Engenharia Química [PDF https://portal.unila.edu.br/graduacao/engenhariaquimica/arquivos/ppc-engenharia-quimica-1.pdf

[16] Walkington, J., Pemberton, P., \& Eastwell, J. (1994). Practical work in engineering: A challenge for distance education. Distance Education, 15 (1), 160-171. https://doi.org/10.1080/0158791940150111 